\title{
Mapping QTLs for physiological traits associated with grain yield under timely and delayed sown conditions in wheat (Triticum aestivum L.)
}

yaswant kumar pankaj ( $\square$ yaswantkumar19994@gmail.com )

Dr. RPCAU

Rajeev Kumar

Kulvinder Singh Gill

Ragupathi Nagarajan

Research Article

Keywords: Heat stress, Double haploid, Stability, Quantitative trait loci and composite interval mapping

Posted Date: January 26th, 2022

DOI: https://doi.org/10.21203/rs.3.rs-1291146/v1

License: (c) (1) This work is licensed under a Creative Commons Attribution 4.0 International License. Read Full License 


\section{Abstract}

Twenty-one quantitative trait loci were discovered across six environments, including three (NS), seven (LS), and eleven (VLS) conditions. The linkage groups 1A, 1B, 2A, 2B, 2D, 3B, 4A, 6A, 6B, and 7D spanned QTLs. For CT, a stable QTL (Qct_rpcau_4A) in the environment E6 has shown a PVE up to $17.85 \%$. The QTL, Qspad_rpcau_2D was found to be stable for SPAD value, explaining the PVE of $15.05 \%$. Whereas, three stable QTLs viz. Qgy_rpcau_3B, Qgy_rpcau_4A and Qgy_rpcau_6A were associated with the chromosomes $3 \mathrm{~B}, 4 \mathrm{~A}$ and $6 \mathrm{~B}$ explaining a PVE of $20.85 \%, 17.43 \%$ and $17.37 \%$ respectively for the trait GY. The interaction of genotype and environment has been shown to be useful in determining the best lines for heat stressed environments. In addition, GXE analysis was performed on the population. In the ranking of genotypes for both mean yield and mean Vs. stability, GGE biplot across the six environments, DH $146,195,60,202,65,155,124,5,201,169,15$, and 170 were ranked closest to ideal and winning genotype; these were highly adapted and most stable lines. The goal of the current investigation was to find the best suitable double haploid lines which can withstand heat-stress and to find those QTLs which are influential to heat stress for the studied traits.

\section{Introduction}

Cereals serve a critical role in satisfying global food demand and ensuring food security. Wheat is produced on 217 million hectares with a global output of 731 million tonnes (http://www.fas.usda.gov) and occupies a vast agricultural area of 30.54 million hectares with a national production of 94.57 million tonnes ${ }^{1}$ (Ramadas et al., 2019). It provides edible grain which forms staple food for billions of people world over ${ }^{2}$ (Verma et al. 2020). The latest United Nations projections indicate that world population will reach 10 billion in the year $2056^{3}$ (Prakash et al. 2019). Climate change-related extinction is a serious restriction in wheat-growing regions. It is prone to heat stress which affects its production on a large Scale ${ }^{4}$ (Pankaj et al. 2021). Over a decade, global wheat output has decreased by up to $5 \%$ while temperatures have risen by $0.13^{\circ} \mathrm{C}^{5}$. (Hatfield et al., 2017). According to Asseng et al. 2015 , each $1^{\circ} \mathrm{C}$ increase in temperature to $23^{\circ} \mathrm{C}$ would cut world wheat yield by $6 \%^{6}$. During the rabi season in 2020 , south asian regions will have maximum and lowest temperatures of $1.54^{\circ} \mathrm{C}$ and $1.08^{\circ} \mathrm{C}$, respectively ${ }^{7}$ (Bhusal et al., 2017). Wheat output in India will be reduced by 4 million tonnes for every $1^{\circ} \mathrm{C}$ increase in temperature. High temperatures have an impact on more than $40 \%$ of the world's wheat-growing region. Wheat yield is affected by high temperatures, either as a consequence of chronic stress at $32^{\circ} \mathrm{C}$ or by rapid heat shock, although only for a short period of time up to $33^{\circ} \mathrm{C}$ and higher. Wheat yields are being impacted by global warming. Heat waves in the United States and Canada, as recorded lately, may have an influence on crops. Heat waves have become increasingly powerful, frequent, and long-lasting, and as global warming continues these trends are expected to worsen. At the morphological, physiological, biochemical, and molecular levels, high temperatures have a profound impact. High temperatures around critical plant growth stages, such as flowering and grain filling, can significantly reduce grain yields ${ }^{8}$ (Ali et al., 2021), while prolonged high temperatures can result in almost total yield loss ${ }^{9}$ ( Semenov et al 2011). At vegetative stage, wheat is more vulnerable to high temperatures during the reproductive stage. 
The temperature at flowering and grain filling stage vary from $12^{\circ} \mathrm{C}$ to $22^{\circ} \mathrm{C}$ on average ${ }^{10}$ (Sharma et al., 2019). The high temperature causes a decrease in grain filling duration, which is followed by a loss in grain weight. In wheat, every $1^{\circ} \mathrm{C}$ increase over $15-20^{\circ} \mathrm{C}$ reduces grain filling time by 2 to 8 days $\mathrm{s}^{11}$ (Xin et al., 2019). Ten days from anthesis until maturity, a high temperature of $35 / 20^{\circ} \mathrm{C}$ reduced grain production by $78 \%$, grain number by $63 \%$ and individual grain weight by $29 \%$. When it comes to physiological processes, photosynthesis is crucial, and high temperatures have a significant impact. In wheat, the optimal temperature for photosynthesis is a broad range of temperatures $\left(20\right.$ to $\left.30^{\circ} \mathrm{C}\right)$; however, at temperatures over $30^{\circ} \mathrm{C}$, the rate of photosynthesis declines significantly regulating biomass output and grain yield.

Various QTLs have already been reported in previous studies for wheat grain yield ${ }^{12}$ (Lopes et al. 2015), Major QTLs for heat tolerance have also been reported on chromosomes 2A and 2B in wheat under heat stress condition. In previous study, wheat have been evaluated in control and heat stress conditions and described as indirect selection criteria for improving grain yield in heat prone environments.

Understanding the genetic control of traits associated with grain yield is essential for the enhancing tolerance to heat in plants. It is now recognized that the effective method for genetic improvement of heat adaptive traits in wheat is marker-assisted selection.

In the study by Pinto et al. (2010) common QTL for both drought and heat adaptation were identified on six chromosomes, namely $1 \mathrm{~B}, 2 \mathrm{~B}, 3 \mathrm{~B}, 4 \mathrm{~A}, 4 \mathrm{~B}$ and $7 \mathrm{~A}^{13}$. These $\mathrm{QTL}$ regions were associated with both agronomic and physiological traits including QTL for grain number, thousand grain weight, canopy temperature, NDVI and chlorophyll content. Likewise, Bennett et al. (2012b) reported two major QTL associated with yield on chromosome $3 \mathrm{~B}^{14}$. The QTL on $3 \mathrm{BL}$ explained up to $22 \%$ of the phenotypic variation for both yield and canopy temperature. The benefits of a cooler crop canopy, influenced by a combination of leaf, spike, and peduncle cooling were correlated with both yield in the field ${ }^{15}$ (Ayeneh et al. 2002) and under controlled conditions ${ }^{16}$ (Hede et al. 1999) and associations with differences in plant morphology were also documented ${ }^{17}$ (Balota et al. 2008). The association mapping method has been used to wheat, allowing for the finding a large number of quantitative trait loci ${ }^{18}$ (Vasantrao et al., 2019). QTL co-localization can also be a powerful way of identifying traits associated with heat tolerance of yield components. These associated traits can give clues about underlying tolerance mechanisms and potentially provide complementary selection criteria for heat tolerance breeding. A breeder needs a handy tool to identify their variety ${ }^{19}$ (Pankaj et al. 2021).

In view of this, the present study was designed (1) to identify QTLs with for the physiological and other traits associated with grain yield in the PBW343/IC252874 population (2) to examine the associations of the heat adaptive traits with grain yield in control and terminal heat stress conditions (3) to discover highyielding and stable DH lines throughout the different environments, three distinct sowing dates, impact of planting dates on wheat yield stability across years.

\section{Materials And Methods}




\section{Plant Materials and field trial}

By crossing two parental genotypes, PBW343 (heat susceptible) and IC252874 (heat tolerant), a double haploid mapping population (DH) comprised of 165 lines was created. The DHs were developed at Washington State University in Pullman, Washington, and evaluated in the Rajendra Prasad Central Agricultural University's research farm in Pusa, Bihar, India ( $\left.25^{\circ} 57^{\prime} 08^{\prime \prime} \mathrm{N} ; 85^{\circ} 40^{\prime} 13^{\prime \prime} \mathrm{E}\right)$. The generations were advanced using an offseason facility at the Punjab Agricultural University's Research Station in Keylong, Himachal Pradesh, India. During the 2017-2018 and 2018-2019 growing seasons, two trials were conducted (Table 1). In each experiment, three replications of 165 doubled haploid lines along with their parents were sown in an alpha lattice design. The experimental plots were made up of two $2 \mathrm{~m}$ long beds with four rows each, spaced $60 \mathrm{~cm}$ apart. The agronomic practices recommended for irrigated and normal fertility ( $125 \mathrm{~kg} \mathrm{~N} ; 55 \mathrm{~kg} \mathrm{P} 205$ and $35 \mathrm{~kg} \mathrm{~K} 20$ ha-1) conditions were followed throughout the 2 years. Full doses of $\mathrm{K} 2 \mathrm{O}$ and P2O5 were applied th the time of sowing. Nitrogen was supplied in the form of split application, $55 \mathrm{~kg} \mathrm{~N}$ ha-1 at sowing, $25 \mathrm{~kg} \mathrm{~N}$ ha- 1 at first irrigation (20 days after sowing) and 35 $\mathrm{kg} \mathrm{N}$ ha-1 at second irrigation (42 days after sowing). Irrigation was provided to the crop at five sensitive growth stages (at crown root initiation Zadok, GS 21; tiller completion Zadok, GS 29; late jointing Zadok, GS 36; flowering Zadok, GS 61; and milk stage Zadok, GS 75) to maintain optimum soil moisture. Weeds were removed manually.The experiment was carried out on three distinct sowing dates, namely November, December, and January, with a gap of twenty-five days between them. In both succeeding crop seasons, the experiment with late sown conditions and very late sown conditions were considered as heat and terminal heat stressed one. To expose the plants at different levels of high temperatures at the time of grain filling, the crop was sown during the second week of each month (Table S1).

\section{Phenotyping}

The grain yield ( $G Y$ in $\mathrm{g}$ ) was estimated by weighing grains of harvested plants from a $2 \mathrm{~m}^{2}$ plot, ignoring boundary impact ${ }^{20}$ (Sayre et al. 1997). TGW was measured by taking random samples of 500 grains from plot yield and weighed. GFD was estimated as the difference in days between anthesis and physiological maturity. The leaf chlorophyll content was measured with the SPAD unit using a portable chlorophyll metre (SPAD-502 Minolta, Spectrum Technologies Inc., Plainfield, IL, USA) at the grain-filling stage. CT values were taken at three development stages (GS55, GS65, and GS83) on bright sunny days between 1200 and $1400 \mathrm{~h}$, using a hand-held infrared thermometer (Mikron Infrared Inc. NJ, USA) positioned at a $30^{\circ}$ angle to the horizontal, $1 \mathrm{~m}$ from the plot boundary, and $50 \mathrm{~cm}$ above the canopy. Only the middle rows of each plot were employed for data collection to reduce competition with surrounding genotypes for water, light, and other resources required for canopy growth.

\section{Genotyping}

The DNA was extracted using coleoptiles (http://www.triticarte.com.au/content/DNA-prepa ration.html). This was done using a consensus $\operatorname{map}^{21}$ (Somers et al. 2004). The thermo cycling programme included a 3 minute denaturation at $94^{\circ} \mathrm{C}, 30$ second cycles at $50 / 65^{\circ} \mathrm{C}, 30$ second cycles at $72^{\circ} \mathrm{C}$, and a final 2 
minute cycle at $72^{\circ} \mathrm{C}$ in Thermal Cycler ${ }^{22}$ (Sharma et al. 2016). The parents' SSR markers were tested for polymorphism on 322 SSRs. 71were polymorphic between parental genotypes (Table S2). The 71 SSRs (gwm, wmc, swm, barc, and cfd) were used to build linkage maps across wheat chromosomes. Polymorphic SSR profiles were visually evaluated by coding PBW343 alleles as "A" and IC252874 alleles as "B." " $H$ " stands for heterozygote and 'NA' for missing bands. Allele bands were seen on $3 \%$ agarose gels (Fig 1).

\section{Linkage map construction and QTL mapping}

The genotyped data of the $\mathrm{DH}$ population was used to generate a linkage map using software MapDisto 2.1.7.1. The Kosambi mapping function and interval position type was used for the conversion of recombination frequency into the genetic distance. QTL analysis was performed using QTL Cartographer v2.5 ${ }^{23}$ (Wang et al., 2010). In the CIM method, forward regression with five background markers, a window size of $10.0 \mathrm{cM}$, and a walking speed of $2 \mathrm{cM}$ were used in the software Windows QTL Cartographer 2.5. The trait setting for Composite interval mapping (CIM) was done using model 6 and used to determine likely QTL positions and a threshold of 1,000 permutation test at $P=0.05$. The putative QTLs were defined as two or more linked markers associated with a trait at LOD $>3.0$. The suggestive QTLs were defined as QTLs where two or more linked markers were detected at $2.0<\mathrm{LOD}<3.0^{28}$ (McIntyre et al. 2010). Here, The LOD value was set as a minimum LOD value 2.0 to keep consider suggestive and minor QTL as well. However, all the QTLs were detected above LOD value 3.0.

\section{Statistical analysis}

During both years, analysis of variance (ANOVA) revealed that genotypes differed considerably in heat tolerance for all variables. GenStat-12.1/2009 (http://www.vsni.co.uk/genstat was used to calculate the Pearson correlation coefficient between the attributes in the trials.

\section{GXE analysis}

The grain yield data from all the six environments (E1, E2, E3, E4, E5 and E6) were subject to GGE biplot analysis to investigate the impacts of GEI on grain yield. GEAR programme is used to determine the influence of the environment $(E)$, genotype $(G)$, and GE interaction. The first two components acquired from the principle components were utilised by GGE biplot software to create the biplot. The fundamental concept for a GGE biplot is shown below. Where $Y i j=$ the mean yield of genotype $i(=1,2, \ldots, n)$ in environment $j(=1,2, \ldots m), \mu$ is the the grand mean, $\beta j$ is the main effect of environment $j,(\mu+\beta j)$ being the mean yield of environment $j, \lambda l$ is the singular value (SV) of Ith principal component (PC), the square of which is the sum of squares explained by $P C l=(l=1,2, \ldots, k$ with $k \leq \min (m, n)$ and $k=2$ for a twodimensional biplot), ६il is the eigenvector of genotype i for $\mathrm{PCl}, \eta \mathrm{lj}$ is the eigenvector of environment $\mathrm{j}$ for $\mathrm{PCl}, \varepsilon \mathrm{ij}$ is the residual associated with genotype $\mathrm{i}$ in environment $\mathrm{j}$. We need to partition the SVs into the genotype and environment eigenvector in order to generate a biplot which we can used during the visual analysis of MET data due to which the above model can be expressed in the form of Where for for genotype $i$ and environment $j$ the $\mathrm{PCl}$ scores are gil and elj respectively. The genotype i presented as a 
point defined by all gil values, and environment $j$ is presented as a point defined by all elj values $(I=1$ and 2 for a two dimensional biplot) in a biplot. If there were the data's that are environment-standardized, to generate the GGE biplot the common formulae would be as follows Where $\mathrm{Sj}$ is the standard deviation in environment $\mathrm{j}, \mathrm{i}=1,2, \ldots ., \mathrm{k}$, gi1 and $\mathrm{e} 1 \mathrm{j}$ are $\mathrm{PC} 1$ scores for genotype $\mathrm{i}$ and environment $\mathrm{j}$, respectively ${ }^{24}$ (Poudel et al., 2020).

\section{Result}

\section{Assessment of heat stress}

Out of three different dates of sowing, the very late sown experiments were the hottest in terms of average minimum and maximum temperatures during vegetative growth and grain fill, and had the highest number of days with temperature $\left(28^{\circ} \mathrm{C}, 31^{\circ} \mathrm{C}\right.$ and $\left.34^{\circ} \mathrm{C}\right)$. The meteorological data for both the cropping season 2017-2018 and, 2018-2019 provided already. An ANOVA of the data collected from 2 years $\times 3$ environments or dates of sowing $\times 5$ trait combinations was performed using the software Genstat V. 15. It showed significant $(p<0.01)$ main effects due to genotypes for all traits studied during both the crop seasons 2017-18 and 2018-19 (Table 2). For the five studied traits, values of correlation coefficients based on data pooled over normal, late and very late sowing conditions are presented in (Fig 2).

\section{Phenotypic analyses for heat tolerance}

Very contrasting differences were found in parental lines for GFD under stress condition. The heattolerant parent, IC 252874, showed non-significant reduction for all yield components, whereas GFD was found highly reduced $(22.8 \%$ and $24.2 \%)$ under late-sown condition in both the years. On the contrary, the heat-sensitive parent, PBW 343, showed significant reduction in GY $(41.2 \%$ and $33.2 \%)$ with little reduction in GFD under late-sown condition in both the years. It was interesting that there was no significant reduction in TGW in both parents under terminal heat stress in very late-sown condition as compared to normal sown. A significant reduction in GFD (17.3\% and 19.0\%) and GY (33.2\% and 30.0\%) was observed in $\mathrm{DH}$ population under heat stress condition across the years.

\section{QTL analysis for heat stress tolerance}

During the crop seasons 2017-18 and 2018-19, composite interval mapping (CIM) discovered a total of twenty one quantitative trait loci (QTLs) over six environments (E1, E2, E3 E4, E5, E6) , with three (NS), seven (LS) and eleven (VLS) conditions. QTLs spanned on linkage groups 1A, 1B, 2A, 2B, 2D, 3B, 4A, 6A, 6B and 7D (Fig 3). The QTLs were detected for the traits viz., grain filling duration (GFD), canopy temperature (CT), chlorophyll (SPAD), thousand grain weight (TGW) and grain yield (GY) respectively. The LOD score of identified QTLs varied from 2.5 (Qtgw_rpcau_2A) to 10.4 (Qspad_rpcau_2D) during the year, 2017-18 and 2018-19, explaining 5.07\% and 15.05\% phenotypic variance (PVE) respectively. Most number of QTLs was detected on chromosome 2B and least on 1A, 6A and 6B. The graph below, a representative graph of QTL hit is depicted (Fig 4). 


\section{QTL for Morpho-physiological traits}

The morpho-physiological traits, canopy temperature (CT) and chlorophyll (SPAD value) was analyzed for QTL mapping. The Prominent QTLs related to CT were found on chromosomes 1B, 2B and 4A. The three QTLs, Qct_rpcau_2B, Qct_rpcau_1B and Qct_rpcau_4A were found in heat stressed environments across the year. Out of the three, one stable QTL (Qct_rpcau_4A) in the environment E6 has shown PVE up to $17.85 \%$. On the other hand, four QTLs appeared for SPAD values which were associated with the chromosome 2D, 4A, 6B and 7D. Out of the four QTLS, Qspad_rpcau_2D, Qspad_rpcau_6B and Qspad_rpcau_7D were found in heat stressed environment whereas Qspad_rpcau_4A was appeared in normal sown condition. The QTL, Qspad_rpcau_2D was found to be stable explaining the PVE of $15.05 \%$.

\section{QTL for grain yield and related attributes}

The three yield and related parameters were analyzed for the mapping study viz. GFD, TGW and GY. A total no. of six QTL was identified for the grain filling duration (GFD), four QTLs each thousand grain weight (TGW) and for grain yield (GY). A stable QTL for GFD (Qgfd_rpcau_2A) was found on chromosome $2 \mathrm{~A}$ and accounted for $16.41 \%$ of PVE. Qtgw_rpcau_1B was identified to be a stable QTL for TGW with the PVE up to $17.54 \%$. For GY, three stable QTLs viz. Qgy_rpcau_3B,

Qgy_rpcau_4A and Qgy_rpcau_6A were associated with the chromosomes 3B, 4A and 6B explaining a PVE of $20.85 \%, 17.43 \%$ and $17.37 \%$ respectively.

\section{GGE biplot (Which-won-where/model )}

For two years, biplot analysis of the double haploid lines revealed a varied response under three distinct sowing dates or enivronments. For normal sowing, late sowing, and very late sown sowing, biplots were created. The polygon was created by connecting the $\mathrm{DH}$ lines that were farther away from the biplot origin, ensuring that all other $\mathrm{DH}$ lines were included. Because they were the farthest from the biplot's origin, the DH lines on the polygon's vertices performed either the best or the worst in one or more year or conditions. The GGE biplot's 'polygon' (which-won-where) view splits the biplot into sectors using perpendicular lines that passes through the polygon sides. The polygon is created by combining the biplot's extreme genotypes. If environments are divided into sectors, different genotypes will win in various sectors, resulting in a crossover GE pattern. The vertex genotype is the winning genotype for an environment or combination of environments in a sector. In contrast, if all environments are classified as belonging to the same sector, a single genotype has the best yield across all conditions. In all the environmental conditions, the vertex genotype in a sector with no environment is regarded a poor performer. Within the polygon, genotypes were less sensitive to location than genotypes at the vertex. In this study, feature of the biplot identified wining genotypes for the trait grain yield fell into 9 or 8 sectors for $\mathrm{Y} 1$ and $\mathrm{Y} 2$ respectively (Fig 5). The vertex or winning DH lines for $\mathrm{GY}$ those were found to be common across the sowing dates (D1, D2, D3, D4, D5, D6) and year (Y1 and Y2) are DH 34, 146, 170, 149, 195 and 60 . Surprisingly, in virtually all settings, the highest actual and anticipated yielding lines are almost identical. This shows that various DH lines triumphed in different areas, and that there was a crossover GE pattern. 


\section{Mean vs. stability model}

The GGE biplot's 'mean vs. stability' perspective explained $75-80 \%$ of genotypic and genotype environment variance across environments at various sowing dates. The arrow on the AEC abscissa indicates in the direction of genotypes with better yield performance and ranks them according to yield performance. Each genotype's stability was investigated by projecting it onto the AEC vertical axis. The most stable genotype had a near-zero projection onto the AEC abscissa (horizontal axis) and was virtually on the AEC abscissa (horizontal axis) (vertical axis). The DH lines for grain yield, DH 145, 125, $107,35,164,18,113,104$, found to be most stable in all the dates (D1, D2, D3, D4, D5, D6) across the year (Y1 and Y2) (Fig 6 ).

\section{Discussion}

The experiment was carried out with a 165 doubled haploid population produced from a PBW343 X IC252874 cross. The different planting dates resulted in a total of six different environmental conditions. The mean minimum and maximum temperatures under late sowed and very late sown circumstances were higher than the normal sown condition for the 2017-2018 and 2018-2019 crop seasons. The very late sown condition had the lowest yield on average for the population because to the higher temperature and longer day duration. During the flowering stage, the crop was more sensitive to high temperatures ${ }^{25}$ (Dolferus et al. 2011). There was considerable variability among the parents of the DH population for the traits studied, reflecting genetic diversity among both the parents and the derived population. For all of the investigated variables present in the $\mathrm{DH}$ lines for heat tolerance, analysis of variance indicated significant ( $p$ 0.01) main effects associated to genotypes. Values of correlation coefficients based on data aggregated across Normal sown, Late sown, and Very Late Sown circumstances for the investigated morpho-physiological and yield related variables.

We could detect 21 QTLs with additive effect for all studied traits in NS, LS and VLS conditions, respectively. This confirms these traits are genetically complex and also inherited quantitatively as previously reported (Lopes et al. 2015) ${ }^{12}$. The results of this study are in agreement with those of reported in previous studies (Azam et al. 2015) ${ }^{26}$. For example, Pinto et al. (2010) reported eight QTLs for GY ${ }^{13}$.

\section{QTL comparison between conditions}

Investigation of a double haploid population in the six (E1, E2, E3, E4, E5 and E6) environmental conditions allowed us to compare detected QTLs for different traits and also to identify common QTLS between the different conditions. In this Study, seven QTLs with common flanking marker were detected between the six environments. The common QTLs were shared on the chromosome 2A, 3B and 4A. The marker, Gwm47-gwm445 flanked the two QTLs, Qtgw_rpcau_2A (E1) and Qgfd_rpcau_2A (E6) for TGW and GFD, respectively. The marker, Gwm533.2-wmc500 was linked to two QTLs for GY and GFD, Qgy _rpcau_3B (E3) and Qgfd_rpcau_3B (E6), respectively. Qgy_rpcau_4A (E3), Qspad_rpcau_4A (E4), and Qct_rpcau_ 4A (E5) were shown to be associated with the marker Cfd71-wmc48. These environment- 
specific QTLs can also be employed to improve breeding efficiency using the marker-assisted selection method. The common QTLs influenced GY, WSC, CMS, PRO, and Fv/Fm in both environments and were found on chromosomes 2B, 2D, 4A, 4B, 5B, and 6A. However, numerous QTLs with significant impacts (such as QChl-4A) were found for different traits in just one of the two environmental conditions ${ }^{27}$ (Hassan et al., 2018). Under heat and drought stress, Pinto et al. 2010 found multiple environmentsensitive QTLs for grain yield and yield-related characteristics in this group ${ }^{13}$.

\section{Co-location and pleiotropy of QTLs}

In the present study, the co-location of two or more QTLs confirmed the strong correlations among the studied traits. For example, Qspad_rpcau_7D and Qgfd_rpcau_7D coincided in their genomic regions with each other and suggested that the strong positive correlation between SPAD values with GFD would come from these co-localized QTLs. Another example of co-location was the QTL near the flanking marker Gwm533.2-wmc500 on chromosome 3B, which affected GY (Qgy_rpcau_3B) and GFD (Qgfd_rpcau_3B) confirmed their significant positive correlations in the heat stress condition. Previous studies have shown similar co-locations; for example, Mclntyre et al. (2010) found multiple co-located QTLs for distinct characteristics in this group; for example, QTLs for WSC and GY were found in the same location on 6D ${ }^{28}$. On chromosome 7D, Tahmasebi et al. 2016 discovered shared QTLs for GY and $\mathrm{SPAD}^{29}$. A linkage between two genes or the pleiotropic influence of one gene might result in common genomic areas for diverse phenotypes ${ }^{13}$ (Pinto et al. 2010). The findings demonstrated, however, that colocated QTLs with adequate effects for grain yield and yield components in non-stress and heat stress conditions might be beneficial for marker assisted selection or gene cloning to develop high-performance genotypes.

\section{Comparison with previous studies}

The results demonstrated that QTLs were mapped for GY trait on chromosomes 2B, 3B, 4A and 6A. Bennett et al. $2012^{14}$ and Hassan et al., $2018^{27}$ has reported that GY was associated with 2B. A QTL was detected which influenced the response of grain weight to a brief heat stress applied at early grain filling in a growth chamber, QTL11 (QHsgw.aww-3B) with the former having the strongest and most reproducible effect ${ }^{30}$ (Shirdelmoghanloo et al., 2016). QTL for more than one yield component HSI colocalized in regions $1 \mathrm{~A}, 2 \mathrm{~A}, 2 \mathrm{~B}$, and $4 \mathrm{~A}$, as well as areas where $\mathrm{HSI}$ co-localized with other phenotypic traits (1B, 2A, 2B, 3B, and 5A) ${ }^{31}$ (Mason et al., 2010). However, we have identified chromosome 6A associated with GY (Qgy_rpcau_6A) which is not found in previous studies. It explained a PVE of $17.37 \%$ in very late sown condition (E6) of the year 2018-19. Therefore it could be a novel QTL for GY and the linked marker Barc206-barc23 could be utilised for MAS. In our study, the QTLs for GFD were harboured on 2A, 2B, 2D, 3B and 7D. Similarly, the QTL responsible for GFD variation was found on chromosome 2D, QHGfd.bhu1-2D was flanked by gwm349 and wPt9797 (5.1cM window), with a mean LOD score of 4.5 and a mean percent PVE of 21.0 during the three years, whereas QHGfd.bhu2-2D was flanked by cfd233and cfd044 (29.8cM window), with a mean percent PVE of 20.6 percent and a mean LOD. On the other hand, we discovered a QTL for GFD on 2D that explains a percent PVE of 13.41 percent on a LOD 
value of 7.232 (Tiwari et al., 2013). In a previous study, two QTLs viz. QGfd.tam-2A and QGfd.tam-2D were also found on chromosome 2A and 2D. Our finding also does comply with the previous result. However, we found $2 \mathrm{~B}, 3 \mathrm{~B}$ and 7D associated with trait GFD in our study but not appeared in previous findings. Hence, these loci could be influenced by heat stress in relation to GFD. In our study, the chromosome $1 A$, 2A, 2B, 2D harboured TGW related QTLs. We have found 4 QTLs for TGW. In heat stressed conditions, a QTL, Qtgw_rpcau_1B, flanked by the marker Wmc44-wmc367, accounted for a percent PVE of 17.54 \%with a LOD value of 8.9 and found to be a stable QTL for TGW. The QTL (Qtgw_rpcau_2A) for TGW was found in normal sown condition with a non significant percent PVE of 5.07\% with the LOD value of 2.5 . Similarly, Tahmasebi et al., 2016 reported a QTL related to TGW found on chromosomes 2A had no significant QQE effects. Our finding matches with the previous results ${ }^{29}$. However, in our case, 1A, 2B and 2D were also associated with QTL related to TGW but previous findings have not shown TGW-QTLs on these above chromosomes. Therefore, these chromosomes and linked marker could harbour vital information related to TGW considering high temperature. Other than the yield parameters, morphophysiological traits like CT and SPAD value were also mapped in relation to heat stress. The CT related QTLs were detected on 1B, 2B and 4A where, Qct_rpcau_4A was found to be stable QTL with the percent PVE of $17.85 \%$. Similarly, the QTL for CT was reported on chromosome 2B, with 15\% PVE ${ }^{33}$ (Paliwal et al., 2012). Tahmasebi et al., 2016 also detected CT related QTL on $1 B^{29}$. Similarly, Pinto et al. (2010) discovered CT related QTL on 1B as being solely associated with stress environments, with SeriM82 alleles dominating adverse impacts (high CT) ${ }^{13}$. In our study, QTL for SPAD value were identified on 2D, 4A and 7D. Qspad_rpcau_2D was detected as a stable QTL for SPAD explaining percent PVE of $15.05 \%$ with the LOD value of 10.04 in heat stressed condition. Similarly, the SPAD QTLs were dispersed on 2D and 7D, explained $4.3 \%-17.3 \%$ (PVE) of the total variation in chlorophyll content ${ }^{29}$ (Tahmasebi et al., 2016). Heat tolerance in field crops, such as bread wheat, is linked to a number of physiological, biochemical, and morphological characteristics ${ }^{27}$ (Hassan et al., 2018). As a result, we examined a variety of physiological and developmental variables to learn more about the components that influence heat responsiveness to grain weight and the basis of the QTL-controlled tolerance mechanisms. QTLS were discovered for each of the traits investigated in this study, demonstrating that they are genetically complex and quantitatively inherited, as previously stated ${ }^{12}$ (Lopes et al. 2015). The findings of this study are in line with those of previous studies ${ }^{26}$ (Azam et al. 2015). In the near future, the population will be genotyped using modern techniques such as Genotypic by sequencing (GBS) to identify SNP linked to heat stress.

\section{GGE Biplot and Mean Vs. Stability}

Based on these findings, we hypothesised that temperatures in the Indo-Gangetic plains climbed somewhat over crop duration but that the pattern remained the same as before. As a result, it's critical to comprehend the unique effects of changed sowing dates and higher temperatures on wheat yield stability in the Indo-Gangetic plains. We discovered differently stable doubled haploid lines for each of these three dates of sowing based on Normal (November), late (December), and very late (January) sown dates. This approach was similarly adopted by Jat et al., 2018 to study stability of diversified wheat 
genotypes ${ }^{34}$.The stability analysis and GXE interaction supported by the QTL analysis data were used to decipher the phenotypic response to normal, late, and very late sown conditions within the population. Performance and stability of genotypes were visualized graphically through the GGE biplot. This can be evaluated by average environment coordination (AEC) method $^{3}$ (Poudel et al., 2019). The average environment has average PC1 and PC2 scores across environments (Purchase et al., 1997). Greater the absolute length of the projection of a genotype indicates more instability. Furthermore, the average yield of genotypes is approximated by the projections of their markers to the AE Cabscissa ${ }^{36}$ (Purchase et al., 1997). The greater the absolute length of the projection of a cultivar, the less stable it is. An ideal genotype should have the highest mean performance and absolute stable (less absolute length of projection). The mean yield of $\mathrm{DH}$ lines for the different dates of sowing varied across environments $(E 1, E 2, E 3, E 4, E 5, E 6)$ and years $(Y 1$ and $Y 2)$ and these results are in agreement with the findings ${ }^{37}$ (Ahmed and Fayyas-ul-Hassan, 2015). According to Yan and Kang 2003, the polygon perspective of a biplot is the best approach to depict genotype-environment interaction patterns and successfully comprehend a biplot ${ }^{38}$. The genotypes near the vertices are the most sensitive genotypes, as well as the ones that have shown specialised adaptability ${ }^{39}$ (Mohammadi et al., 2009). They have a lesser or reduced level of stability. The vertex genotypes were the most sensitive genotypes, according to Yan and Tinker's results, since they are the farthest from the origin in their direction. These genotypes are known as vertex genotypes because they have the greatest distance from the biplot's origin in their directions. The genotypes closest to the origin are the most stable. In this study, feature of the biplot identified wining genotypes for the trait GY fell into 9 or 8 sectors for both the year $\mathrm{Y} 1$ and $\mathrm{Y} 2$. Similarly, a polygon view of the GGY biplot showed environments divided into 2 or 3 sectors across all management techniques for locations BR, MP, and PB. This suggests that various genotypes triumphed in different areas and that there was a crossover GE pattern ${ }^{34}$ (Jat et al., 2018). The vertex or winning DH lines for GY those were found to be common across the sowing dates (D1, D2, D3, D4, D5, D6) and year (Y1 and Y2) are DH 34, 146, 170, 149, 195 and 60 . The GGE biplot is a useful statistical tool for comparing the performance of genotypes in various contexts. The GGE biplot's polygon view revealed the ideal genotype in each environment. The GGE biplot's "which-won-where" aspect is a useful visual tool for megaenvironment study ${ }^{24}$ (Poudel et al., 2020). The 'average environment coordinate' (AEC) approach of GGE biplot may be referred to as the 'mean vs. stability' view (Yan et al., 2007) since it is based on genotypefocused singular value partitioning $(S V P=1)^{40}$. Genotype comparisons based on mean performance and stability across environments within a mega-environment are made easier with this perspective. Mohammadi et al., 2009 also looked at total crop entries in six different conditions ${ }^{39}$. The genotypes were further divided into two groups based on the average tester coordinates: high yielding and poor yielding (ATC). The line that passes across the origin demonstrates genotype stability. The vertical black line is a performance line that runs through the biplot's origin and aids in determining a genotype's mean performance, with the right side from the origin exhibiting greater mean grain yield performance. The projections of their markers on the average-tester axis resemble the cultivars' average yield ${ }^{24}$ (Poudel et al., 2020). The most stable DH lines for GY were DH 145, 125, 107, 35, 164, 18, 113, 104, found to be most stable in all the dates (D1, D2, D3, D4, D5, D6) across the year (Y1 and Y2). Elbasyoni et al., 2018 also 
reported similar results in their study ${ }^{41}$. Overall, the pattern of $\mathrm{DH}$ lines stability varied across the environment and different dates of sowing. To uncover reliable stable lines over different environments, more multi-location trials would be conducted at wheat growing zones. The $\mathrm{G} X \mathrm{E}$ interaction study might potentially aid in the assessment of heat stress genotypes. This will aid in the pyramiding of DH lines in order to transfer traits directly.

\section{Declarations}

The authors declare no competing interest.

Acknowledgement/Funding - The work was supported by United States Agency for International Development-Biotechnology Industry Research Assistance Council (Reference number:

BIRAC/TG/USAID/08/2014). The Acknowledgement to the Department of Agricultural Biotechnology and Molecular Biology, Rajendra Prasad Central Agricultural University, Pusa, Bihar and Department of Biotechnology, Government of India.

\section{References}

Ramadas S, Kiran Kumar T M \& Singh G P, Wheat Production in India: Trends and Prospects, Recent Advances in Grain Crops Research, Farooq Shah, Zafar Khan, Amjad Iqbal, Metin Turan and Murat Olgun, IntechOpen, (2019).

Verma S K, Chaurasia S K, Pankaj Y K \& Kumar R, Study on the genetic variability and pathogenicity assessment among isolates of spot blotch causing fungi (Bipolaris sorokiniana) in wheat (Triticum aestivum L.), Plant Physiol Rep, 25 (2020) 255-267.

Prakash N, Pankaj Y K, Kumar R, Kumar P \& Jat R K, Genetic diversity for submergence tolerance in rice ( Oryza sativa L.) Utilizing SSR Markers, Appl Biol Res, 21(2019)151-157.

Pankaj Y K, Kumar R, Pal L, Nagarajan R, Gill K S, Kumar V \& Panigrahi S, Mapping QTLs for phenotypic and morpho-physiological traits related to grain yield under late sown conditions conditions in wheat (Triticum aestivum L.), (2021)

Hatfield J L, Wright-Morton L \& Hall B, Vulnerability of grain crops and croplands in the Midwest to climatic variability and adaptation strategies, Clim Change, 146 (2017) 263-275.

Asseng S, Ewert F, Martre P, Rötter R P, Lobell D B \&Cammarao D, Rising temperatures reduce global wheat production, Nature Clim Change, 5 (2015) 143-147.

Bhusal N, Sarial AK, Sharma P \& Sareen S, Mapping QTLs for grain yield components in wheat under heat stress, PLOS ONE, 12 (2017) 12. 
Ali I, Tang L, Dai J, Kang M, Mahmood A, Wang W, Liu B, Liu L, Cao W \& Zhu Y, Responses of Grain Yield and Yield Related Parameters to Post-Heading Low-Temperature Stress in Japonica Rice, Plants, 10(2021)1425.

Semenov M A, Donatelli M, Stratonovitch P, Chatzidaki E \& Baruth B, Clim Res, 44(2010) 3-15

Sharma D, Singh R, Tiwari R, Kumar R \& Gupta V, Wheat Responses and Tolerance to Terminal Heat Stress: A Review. In: M Hasanuzzaman, K Nahar \& Hossain M A, Wheat Production in Changing Environments: Responses, Adaptation and Tolerance, (2019) 149-173

Xin M, Peng H, Ni Z, Yao Y, Hu Z \& Sun Q, Wheat responses and tolerance to high temperature. In wheat production in changing environments, (2019) 139-147.

Lopes M S, Dreisigacker S, Peñ A R J, Sukumaran S \& Reynolds M P, Genetic characterization of the wheat association mapping initiative (WAMI) panel for dissection of complex traits in spring wheat, Theor Appl Gene, 128(2015), 453-464.

Pinto R S, Reynolds M P, Mathews K L, McIntyre C L \& Olivares-Villegas J J, Chapman SC, Heat and drought adaptive QTL in a wheat population designed to minimize confounding agronomic effects, Theor App/ Genetics, 121 (2010)1001-1021

Bennett D, Reynolds M, Mullan D, Izanloo A, Langridge P \& Schnurbusch T, Detection of two major grain yield QTL in bread wheat (Triticum aestivum L.) under heat, drought and high yield potential environments, Theor Appl Genet, 125(2012a) 1473-1485.

Ayeneh A, Van Ginkel M, Reynolds M P \& Ammar K, Comparison of leaf, spike, peduncle and canopy temperature depression in wheat under heat stress, Field Crops Res, 79(2002) 173-184.

Hede A R, Skovmand B, Reynolds M P, Crossa J, Vilhelmsen A L \& Stolen O, Evaluating genetic diversity for heat tolerance traits in Mexican wheat landraces. Genet Res, Crop Evol, 46 (1999) 37-45.

Balota M, William A P, Evett S R \& Peters T R, Morphological and physiological traits associated with canopy temperature depression in three closely related wheat lines, Crop Sci, 48(2008) 1897-1910

Vasantrao J M, Pankaj Y K \& Kumar R, Characterization of wheat (Triticum aestivum L.) genotypes unraveled by molecular markers considering heat stress. Indian J Biotechnol,18(2019) 204-213.

Pankaj YK, Kumar R, Pal L, Nagarajan R, Gill KS, Kumar V \& Panigrahi S, Performance and yield stability of doubled haploid population of wheat (Triticum aestivum L.) under high temperature regime, (2021) AgriRxiv. https:// doi. org/ 10. 31220/ agriR xiv. 2021. 00088

Sayre K, Rajaram S \& Fischer R, Yield potential progress in shortbread wheat in northwest Mexico, Crop Sci, 37(1997) 36-42. 
Somers D J, Isaac P \& Edwards K, A high-density microsatellite consensus map for bread wheat (Triticum aestivum L.), Theor App/ Genetics, 109(2004)1105-1114

Sharma P, Sareen S, Saini M \& S Shefali, Assessing genetic variation for heat stress tolerance in Indian bread wheat genotypes using morpho-physiological traits and molecular markers, Plant Genetic Resour, 1(2016)1-9

Wang S, Basten CJ and Zeng ZB (2010) Windows QTL Cartographer 2.5. Department of statistics, North Carolina State University, Raleigh, NC.

Poudel M R, Ghimire S , Pandey M P , Dhakal K, Thapa D B \& Poudel H K, Yield Stability Analysis of Wheat Genotypes at Irrigated, Heat Stress and Drought Condition, J Biol Today's World 9(2020) 220.

Dolferus R, Ji XM \&Richards RA, Abiotic stress and control of grain number in cereals, Plant Sci, 181 (2011) 331-341.

Azam F I, Chang X P \& Jing R L, Mapping QTL for chlorophyll fluorescence kinetics parameters at seedling stage as indicators of heat tolerance in wheat. Euphytica, 202 (2015) 245-258.

Hassan F S C, Solouki M \& Fakheri B A, Mapping QTLs for physiological and biochemical traits related to grain yield under control and terminal heat stress conditions in bread wheat (Triticum aestivum L.), Physiol Mol Biol Plants, 24 (2018) 1231-1243.

McIntyre C L, Mathews L, Ratty A, Chapman S C, Drenth J, Ghaderi M, Reynolds M \& Shorter R, Molecular detection of genomic regions associated with grain yield and yield- related components in an elite bread wheat cross evaluated under irrigated and rainfed conditions, Theor App/ Genet, 120: (2010) 527-541.

Tahmasebi S, Heidari B, Pakniyat H \& Mclntyre C L, Mapping QTLs associated with agronomic and physiological traits under terminal drought and heat stress conditions in wheat (Triticum aestivum L.), Genome, 60 (2016)26-45

Shirdelmoghanloo H, Taylor J D, Lohraseb I, Rabie H, Brien C, Timmins A, Martin P, Mather D E, Emebiri L \& Collins N C, A QTL on the short arm of wheat (Triticum aestivum L.) chromosome 3B affects the stability of grain weight in plants exposed to a brief heat shock early in grain filling, BMC Plant Biol, 16(2016)100.

Mason R E, Mondal S, Beecher F W, Pacheco A, Jampala B \& Ibrahah A M H, et al. QTL associated with heat susceptibility index in wheat (Triticum aestivum $\mathrm{L}$.) under short-term reproductive stage heat stress, Euphytica, 174(2010) 423-436.

Tiwari C, Wallwork H, Kumar U, Dhari R, Arun B, Mishra VK, Joshi AK Molecular mapping of high temperature tolerance in bread wheat adapted to the Eastern Gangetic Plain region of India, Field Crops Res, 154 (2013) 201-210 
Paliwal R, Röder M S, Kumar U, Srivastava J P, Joshi A K, QTL mapping of terminal heat tolerance in hexaploid wheat (T. aestivum L.), Theor Appl Genet, 125(2012) 561-575.

Jat R K, Singh P, Jat M L, Dia M, Sidhu HS, Jat S L, Bijarniya D \& Ridaura S L, Heat stress and yield stability of wheat genotypes under different sowing dates across agro-ecosystems in India, Field Crops Research, 218 (2018) 33-50.

Poudel M R, Ghimire S K, Pandey M P, Dhakal K H, Thapa D B \& Khadka D K, Assessing genetic diversity of drought and heat stress tolerance of Nepalese wheat genotypes by SSR markers, Eurasia J Biosci, 13 (2019) 941-948.

Purchase $\mathrm{J}$ L, Parametric analysis to describe genotype $\mathrm{x}$ environment interaction and yield stability in winter wheat. S Afr J Plant Soil. 17 (1997) 101-107.

Ahmed M \& Fayyas-ul-Hassan, Response of spring wheat (Triticum aestivum) quality traits and yield to sowing date, PLoS One 10 (2015) 4.

Yan W \& Kang M S, GGE Biplot Analysis: A Graphical Tool for Breeders, Geneticists and Agronomists. 1st Edn. CRC Press LLC., Boca Roton, Florida, (2003) 271

Mohammadi R, Amri A, Haghparast R, Sadeghzadeh D, Armion M \& Ahmadi M M, Pattern analysis of genotype-by-environment interaction for grain yield in durum wheat, J Agri Sci Cambridge,147 (2009), 537-545.

Yan W, Kang M S, Ma B, Woods S \& Cornelius P L, GGE biplot vs. AMMI analysis of genotype-byenvironment data, Crop Sci, 47 (2007) 643-653.

41. Elbasyoni IS, Performance and Stability of Commercial Wheat Cultivars under Terminal Heat Stress, Agronomy, 4 (2018) 37.

\section{Tables}

Table 1: Indication of Year, sowing dates and environments

\begin{tabular}{|l|l|l|l|}
\hline Year & Sowing Month & Environment & Sowing Condition \\
\hline Y1(2017-18) & D1 (November) & ENV1 & Normal Sown (NS) \\
\hline & D2(December) & ENV2 & Late Sown (LS) \\
\hline & D3(January) & ENV3 & Very Late Sown (VLS) \\
\hline Y2(2018-19) & D4 (November) & ENV4 & Normal Sown (NS) \\
\hline & D5(December) & ENV5 & Late Sown (LS) \\
\hline & D6(January) & ENV6 & Very Late Sown (VLS) \\
\hline
\end{tabular}


Table 2: Pooled Analysis of variance for different phonological and yield traits

\begin{tabular}{|l|l|l|l|l|l|l|}
\hline Source of Variation & df & \multicolumn{1}{c|}{ GFD } & CT & SPAD & TGW & \multicolumn{1}{c|}{ GY } \\
\hline Env & 5 & 1442.53 & 1216.21 & 5.93 & 61.43 & 1360.88 \\
\hline Rep & 2 & 8.9 & 2.38 & 2.08 & 4.30 & 2.06 \\
\hline Block X Rep & 48 & 10.14 & 4.42 & 3.48 & 6.50 & 9.65 \\
\hline Line & 166 & 14.04 & 5.69 & 5.32 & 4.25 & 4.02 \\
\hline EnvX Line & 830 & 16.50 & 2.58 & 3.54 & 3.02 & 5.04 \\
\hline
\end{tabular}

\begin{tabular}{|c|c|c|c|c|c|}
\hline Environment & Trait & QTL Name & Marker interval & $\begin{array}{l}\text { LOD } \\
\text { score }\end{array}$ & $\begin{array}{l}\text { PVE } \\
\%\end{array}$ \\
\hline E1(2017-18) & Thousand Grain Weight & Qtgw_rpcau_2A & Gwm47-gwm445 & 2.5 & 5.07 \\
\hline \multirow[t]{3}{*}{ E2(2017-18) } & $\begin{array}{l}\text { Soil plant analysis } \\
\text { development }\end{array}$ & Qspad_rpcau_7D & $\begin{array}{l}\text { Barc184- } \\
\text { wmc450 }\end{array}$ & 6.5 & 12.18 \\
\hline & Grain Yield & Qgy_rpcau_2B & $\begin{array}{l}\text { Gwm614- } \\
\text { barc124 }\end{array}$ & 4.96 & 10.83 \\
\hline & Canopy temperature & Qct_rpcau $2 B$ & Wmc25-wmc154 & 7.43 & 11.83 \\
\hline \multirow[t]{6}{*}{ E3(2017-18) } & Thousand Grain Weight & Qtgw_rpcau_1A & Wmc95-gdm136 & 4.07 & 9.74 \\
\hline & Thousand Grain Weight & $Q_{t g} w_{-} r p c a u_{-} 1 B$ & Wmc44-wmc367 & 8.9 & 17.54 \\
\hline & Grain Yield & Qgy_rpcau_3B & $\begin{array}{l}\text { Gwm533.2- } \\
\text { wmc500(C6) }\end{array}$ & 9.39 & 20.85 \\
\hline & Grain Yield & Qgy_rpcau_4A & $\begin{array}{l}\text { Cfd71- } \\
\text { wmc48(c7) }\end{array}$ & 6.04 & 17.43 \\
\hline & $\begin{array}{l}\text { Soil plant analysis } \\
\text { development }\end{array}$ & Qspad_rpcau_2D & $\begin{array}{l}\text { Wmc470- } \\
\text { gwm484 }\end{array}$ & 10.4 & 15.05 \\
\hline & Grain filling duration & Qgfd_rpcau_2B & $\begin{array}{l}\text { Wmc213- } \\
\text { barc200 }\end{array}$ & 6.78 & 10.64 \\
\hline \multirow[t]{2}{*}{ E4(2018-19) } & $\begin{array}{l}\text { Soil plant analysis } \\
\text { development }\end{array}$ & Qspad_rpcau_4A & $\begin{array}{l}\text { Cfd71- } \\
\text { wmc48(c7) }\end{array}$ & 4.4 & 7.04 \\
\hline & Grain filling duration & Qgfd_rpcau_2D & $\begin{array}{l}\text { Gwm484- } \\
\text { gwm122 }\end{array}$ & 7.1 & 13.54 \\
\hline \multirow[t]{4}{*}{ E5(2018-19) } & Canopy temperature & Qct_rpcau_1B & Wmc719-wmc44 & 6.4 & 11.67 \\
\hline & Thousand Grain Weight & Qtgw_rpcau_2D & $\begin{array}{l}\text { Wmc112- } \\
\text { gwm455 }\end{array}$ & 5.9 & 9.04 \\
\hline & Grain filling duration & Qgfd_rpcau_2B & $\begin{array}{l}\text { Barc200- } \\
\text { gwm257 }\end{array}$ & 5.03 & 8.28 \\
\hline & $\begin{array}{l}\text { Soil plant analysis } \\
\text { development }\end{array}$ & Qspad_rpcau_6B & $\begin{array}{l}\text { Gwm191- } \\
\text { wmc737 }\end{array}$ & 5.3 & 8.68 \\
\hline \multirow[t]{5}{*}{ E6(2018-19) } & Canopy temperature & $Q c t_{-} r p c a u_{-} 4 A$ & Cfd71-wmc48 & 6.04 & 17.85 \\
\hline & Grain filling duration & Qgfd_rpcau_2A & Gwm47-gwm445 & 3.43 & 16.41 \\
\hline & Grain filling duration & Qgfd_rpcau_3B & $\begin{array}{l}\text { Gwm533.2- } \\
\text { wmc500 }\end{array}$ & 7.39 & 20.85 \\
\hline & Grain filling duration & Qgfd_rpcau_7D & Cfd41-gdm88 & 7.2 & 13.41 \\
\hline & Grain Yield & Qgy_rpcau_6A & Barc206-barc23 & 8.03 & 17.37 \\
\hline
\end{tabular}


Table 3: Quantitative trait loci detected for grain filling duration, physiological and yield traits in both years 2017-2018 and 2018-2019

\section{Figures}

\section{Figure 1}

The representative image of wmc500 (SSR marker) showing the marker segregation of 1:1 mendelian ratio in the DH population of PBW 343/IC 252874

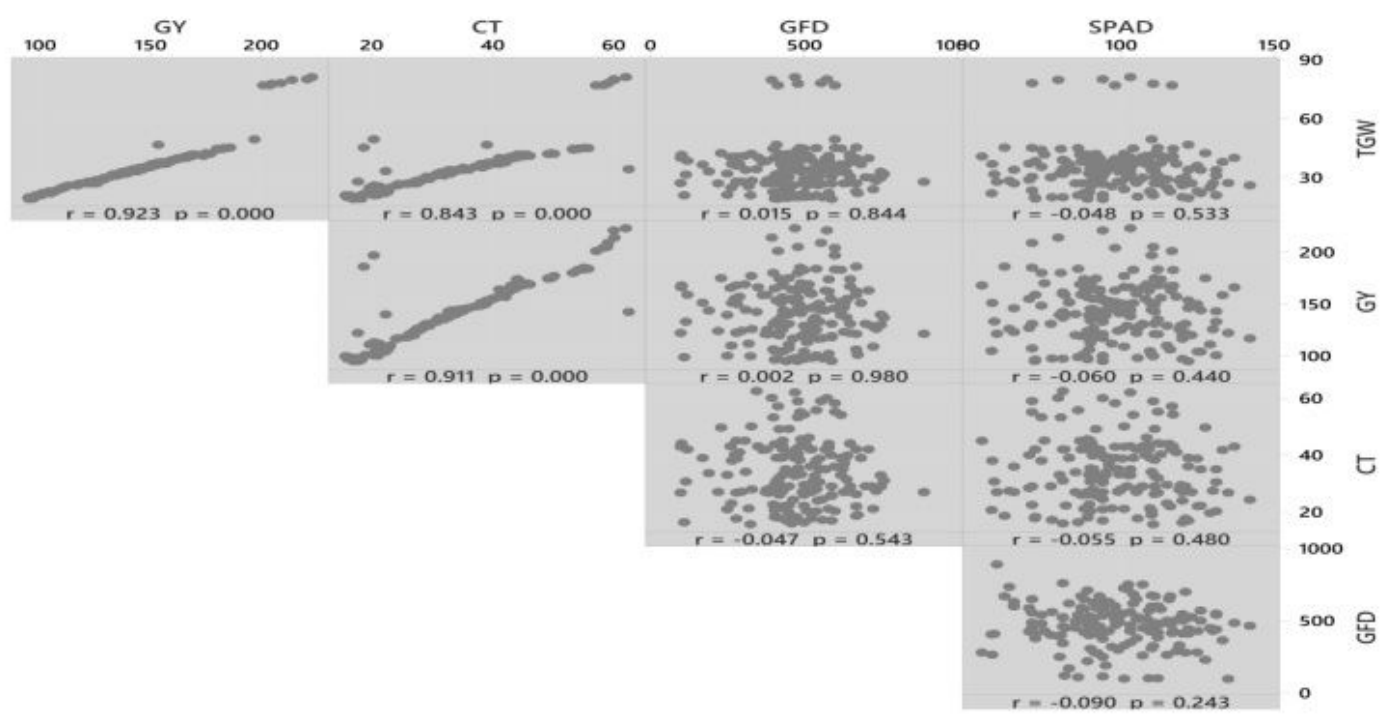

\section{Figure 2}

Pearson correlations between yield and other traits estimated in trial in the PBW343 X IC252874 DH population. 
cM $\mathrm{C} 1$

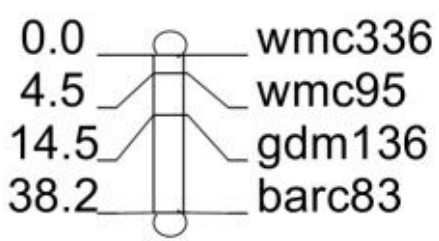

cM C5

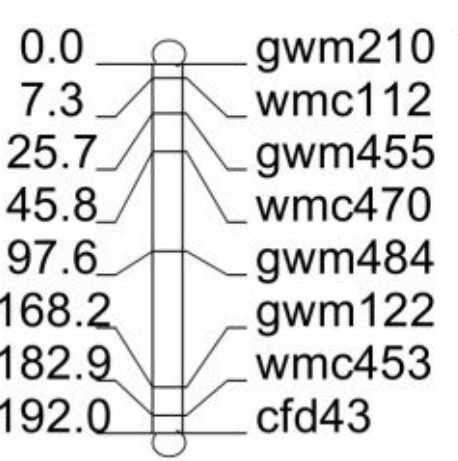

\section{cM $\quad \mathrm{C} 10$}

cM C9

0.0

38.6

94.0

134.3

173.7

216.9 239.4
cM $\mathrm{C} 2$

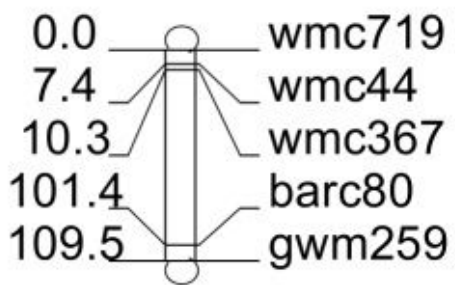

cM $\mathrm{C} 6$



0.0 122.3 200.8 259.2 329.7 386.0 426.3 465.7 506.9 557.4 585.4
cM C3

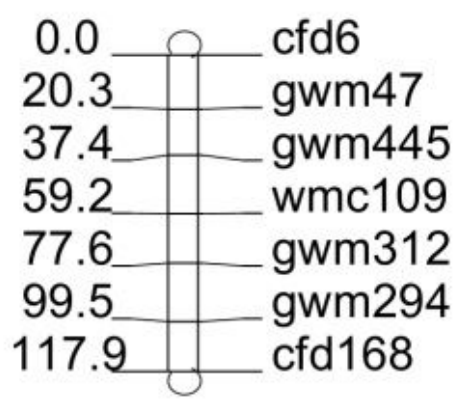

cM C4
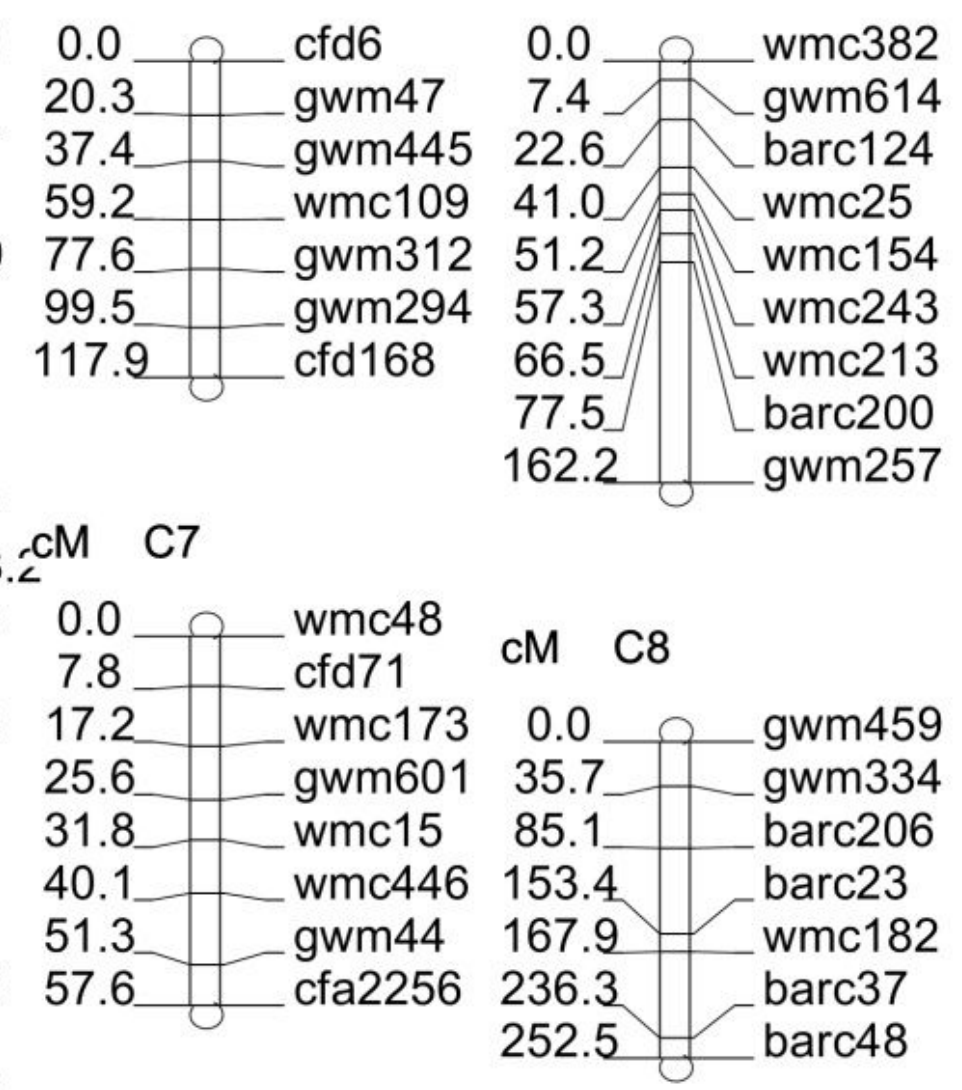

\section{Figure 3}

Linkage map for physiological and yield components in the PBW 343/IC 22874 DHs. QTL detected in both the year 2017-18-19. Markers positions were calculated using the Kosambi mapping function and are listed in $\mathrm{cM}$ position from the top of each linkage group. 



\section{Figure 4}

LOD plots obtained by CIM for the QTL mapping to chromosomes C1-1A, C2-1D, C3-2B, C4-2D, C5-3B, C64D, C7-5B, C8-6D.Vertical lines indicate the threshold LOD score for calling a QTL. The chromosomes short arm appears on the top. Single, open-thick triangles indicate the probable position of the centromere. 
The polygon (which-won-where) view of genotype main effects plus genotype xenvironment interaction effect (GGE) biplot of grain yield of DH lines tested in 2 years, over 3 different dates of sowing.

\section{Figure 6}

The mean vs. stability view of main effects plus genotype $\times$ environment interaction effect (GGE) biplot of grain yield of DH lines tested in tested in 2 years, over 3 different dates of sowing.

\section{Supplementary Files}

This is a list of supplementary files associated with this preprint. Click to download.

- TablesS1andS2.docx 